\title{
Let Me Get My Manager: The Effects of Participation in Cocreated Service Recovery on Frontline Employees
}

\author{
Michael C. Peasley and Joshua T. Coleman
}

\begin{abstract}
No firm can completely escape service failure, and when a failure occurs, a firm's reaction has implications on the customer and the employee. While customer cocreation of value is an important part of the service recovery process (Vargo and Lusch 2004), frontline employees (FLE) are a critical part of the equation as well. FLEs are different from other employees in that they are often the first point of contact for customers and are seemingly placed directly in between the company and customers (Anderson and Onyemah 2006). When a customer experiences a service failure, the FLE has an opportunity to provide a solution to the customer's needs. The customer usually wants a fair and efficient response, and while the employee would prefer to provide a positive and swift solution, it is unknown if they would feel more comfortable providing the service recovery or passing the customer on to a superior.

Drawing on self-determination theory (Deci and Ryan 1985), the purpose of the current study is to examine the impact of cocreated service recovery on FLEs' task motivation and service recovery performance. Self-determination theory (SDT) is rooted in the belief that humans are intrinsically motivated to grow and achieve and will even engage in uninteresting tasks when their value is understood. Through using SDT as a framework to integrate employee literature with literature on service recovery, the current research links FLE involvement in cocreated service recovery with service recovery performance. The present research posits that in attempting a cocreated service recovery, employees being provided with the autonomy to cocreate will have higher service recovery task motivation and perform service recovery at a higher level.
\end{abstract}

\section{References available upon request.}

M.C. Peasley $(\bowtie) \bullet J . T$. Coleman

University of Memphis, Memphis, TN 38152, USA

e-mail: mcpasley@memphis.edu; jtcleman@memphis.edu 